\title{
Journal of Professional Communication

\section{A reflection on the evolution of the field of professional communication}

\author{
Alex Sévigny ${ }^{\star}$, Terence (Terry) Flynn \\ McMaster University, Hamilton (Canada)
}

A R T I C L E I N F O

Article Type:

Editorial

Article History:

Received: 2010-12-23

Revised: 2011-02-25

Accepted: 2011-02-25

Key Words:

Professional Communication

Public Relations

Promotionalism

Communication Metrics

Journalism

\section{A B S T R A C T}

This editorial describes the birth of the Journal of Professional Communication (JPC). It discusses how four fields - public relations, promotionalism (including advertising and advocacy), communication metrics and journalism - appear to be converging into a blended profession, which requires an increasingly similar set of skills and faces many common ethical questions. The authors describe how the advent of social media and a return to oral culture, predicted by Marshall McLuhan, has heralded this convergence. JPC's conception is also discussed: an interdisciplinary venue for practitioners, academics, artists, professional researchers, journalists and policy makers to explore this emerging convergence, exchange ideas and debate current and historic issues in and across their diverse fields.

(C)Journal of Professional Communication, all rights reserved.

$\mathrm{T}$ his journal was born of a conversation between two professional communicators - one who had spent the greater part of his working life as a public relations consultant and the other who had devoted most of his life to research and teaching. The conversation ranged from politics and journalism to public relations and advertising, from education to evaluation. As the hours passed, one point recurred consistently: the interests of professional communicators who practice and teach those disciplines are converging rapidly. We discussed the challenges of communicating in the complex, frenetic environment we now live and work in, where new technologies stimulate all our senses, imbuing much of what we hear, see, smell, taste and touch with communicative intent. We debated whether the radical changes in our information-overloaded society were causing the divided fields of communications to converge or simply collaborate. In the end, we agreed that this discussion required further dialogue and deliberation with others, in Academe, policy circles and in the communications industries.

${ }^{\star}$ Corresponding author. (Alex Sévigny) 
Thus was born the concept of a hybrid, peer-reviewed journal where professional communicators, academics, artists, students and policy makers could have an open and ongoing discussion about the evolving interests of the many fields that fall under the umbrella of professional communication. Whether you work in corporate communications, not-for-profits, a political office, government relations, the media, communications management, publishing, journalism, advertising, communication and opinion measurement, or any other area where professional communication is practiced, you may have felt that change is in the air.

During the last two decades, we have witnessed and experienced the blurring of lines between public relations, promotionalism and advocacy (including advertising or marketing communications), traditional and citizen journalism, and communication, audience and opinion measurement. This change goes beyond simple integration of tactics, strategies and platforms. It eclipses who manages and controls communications within organizations. In essence it is a fundamental shift away from a traditional form of controlled communications to an era of self-determined, on-demand, user-centric content co-creation.

The culture and context of professional communication is changing at both an alarming and exhilarating rate. Traditional forms of communication have been supplemented by the speed and reach of new social media outlets. Communicating in this turbulent environment has never been easier and yet never presented more complex problems for the management of reputation and the resolution of crises. The processes of creation, distribution and redistribution of content are becoming effortless, as the traditional walls and gates of control have begun to fall. Some might argue that this new era has seen communicative power wrestled out of the hands of the media and organizational elites, to rest in keyboards at the fingertips of individuals and community groups. Others will argue that while we have witnessed an increasing level of influence through individual action, powerful media and corporate elites still have the ability and resources to control the channels and technology of communication, which shape collective and individual imagination and consciousness.

Professional communicators, policy makers and scholars are trying to make sense of this new media-saturated era with its rapidly multiplying media and technologies. From the "old" technologies of email and websites to the new realms of social media, geolocation and participatory culture, communicators are searching for more meaningful forums of engagement with their publics. At the same time, newer technologies and platforms are being launched and adopted by evangelists of information and communication technology, creating uncertainty, anxiety and imbalance. In fact, each revolutionary new communication technology causes a change in who controls the flow of information through communication.

Recipients and consumers of communication are also finding it difficult to 
cope with the ocean of information in which their minds and senses are bathed. Indeed, an important question to ask is how this growing list of technologies and tools is reshaping the human condition itself. How is society making sense of the concepts of self, culture and social life within these new conditions? How are people receiving and processing this tidal wave of information and what impact will it have on how professional communicators engage with them in the future? How are artists, designers and video game makers responding to this new reality? How is the world of sound and music, made so pervasive by the iPod, creating meaningful experiences and helping to interpret the deluge of information that is upon us? These questions are fundamental to the future of communication in Canada and around the world. This journal was founded to explore these questions from the point of view of professional communication.

\section{Our culture is shifting from text to talk}

Marshall McLuhan, the great Canadian theorist of communication and culture, spent much of his prolific career developing the theory that electronic technology is moving our culture away from the linear strictures of print toward the open and multifaceted world of oral culture. What this means is a fundamental shift in the way that messages are communicated, truths are established, and our perceptions of the world are organized.

Linear culture was strongly rule-bound and constrained by the requirements of the printed word. Once a word is printed on paper, there is a longterm record of that word. The opinions the word expresses are locked in perpetuity. Most of our communications to one another, up to the advent of the World Wide Web and social media, were done in print. With the arrival of these digital communication technologies, however, our culture started to undergo a radical shift. It lurched away from the order and structure of print, toward the shifting sands of oral communication.

The first shift, from paper to digital, meant that our communication could be changed and altered at will. No longer was it so terribly onerous to revise a news story or an essay once it was produced. Rather, we faced writing that behaved more like conversation. The story would change as events unfolded, as though spoken by a town crier instead of a scribe. As Google News creator, Krishna Bharat has stated:

Why is it that a thousand people come up with approximately the same reading of matters? Why couldn't there be five readings? And meanwhile use that energy to observe something else, equally important, that is currently being neglected (Fallows, 2010). 
This comment suggests that how the news is produced, consumed and interpreted has changed in a digital world. Rather than being a cumulative compendium of solid ideas, where one news article builds upon another, news becomes a cacophonous and conformist space. Now, while the effects of this are having a powerful impact on how the news is created and written up, it is also indicative of a larger tendency in the culture.

The movement from print to oral culture means that rhetoric and influence are regaining some of the power they lost with the shift to print. In fact, the concept of persuasion through strategic, well-crafted and pleasing expression appears to be becoming more important for gaining power and influence in society. This means that the professional communicator is becoming a key part of any common effort in business, social life, politics and popular culture. The profession must reconsider how it defines itself, and in particular how it defines its boundaries and relationships to neighbouring professions. As well, it must define its relationship to the concept of influence, which seems to be rapidly becoming a serious currency in the oral culture that we are developing.

Another great thinker - also a Canadian - Harold Innis, made a powerful point, developing the idea through his life's work that new communication technologies create struggles not only between groups of people, but also between different types of ideas. What types of ideas will be central to the oral culture currently emerging?

Following the initial communications revolution introduced by the World Wide Web, we have seen the evolution of social media, which has in turn created a suite of new information appliances such as tablet computers with audio and video capabilities built-in. At first, social media technologies were largely print-based, with the prevalence of easily manipulated blogging systems such as Wordpress and Blogger, and microblogging services such as Twitter, but this appears to be a transitional moment.

It appears, however, that this reliance on print is just a way station in the social media journey that lies before us. The transformation of social media from print to oral culture is gathering speed, with the evolution of social video and audio. In a few short years, the trend toward social video sharing via Twitter and other such services will grow, and the balance of content shared via social media will hit a tipping point, shifting from text to talk. Next generation blogging platforms such as Tumblr presage this turning of the tide, as do the efforts to promote a more organized and structured means of video sharing by Apple Inc. and Google through their respective social media commerce platforms and information appliances, such as the iPad or the Android tablet. Social networking technologies are quickly moving from privileging the linear word and the still image to favouring video and audio. The video hangouts that Google+ offers, which accommodate up to 10 participants at once, are an 
example of this trend. This emerging state of affairs announces a new world of conversational media, in which spoken culture and the moving image replace print and paper as the predominant media for exchanging our stories. The emphasis in this developing world of social media will be on mobility, cloud computing, the developing HTML5 standard, and device-specific internet applications. Being able to understand, criticize and strategically deploy all of these emerging phenomena will soon be at the core of professional communication practice.

\section{The pillars of professional communication: four professions in evolution}

The emergent massively networked society is creating a heaving sea for those professions that have traditionally been the guardians of image, message and opinion. Many fear being swept under by the waves of change and seek to navigate to calmer waters and eventually to safe harbour. To ensure the success of that journey, practitioners, policy makers and academics need to explore how the component fields of professional communication might evolve or converge to better understand and anticipate their interconnected future. What is this new and emerging field of professional communication and who falls under this umbrella?

The individual fields of communication are being transformed by changes in technology and in our culture. As social media draws us away from print and more deeply into conversation, the walls between the professions of communication have been crumbling. Journalism, promotionalism, communication measurement and public relations/public affairs are converging, forcing the modern practitioner to understand the emergent rules and norms that bridge the four fields. This demands common theoretical reasoning and ethical frameworks that pose the best practices as well as the moral hazards that exist in the grey areas between the fields.

It is at this nexus that the interdisciplinary field of professional communication exists. Recognizing common theoretical underpinnings and skill sets that stem from an understanding of: how people relate to one another, how governments communicate, how persuasion, influence and rhetoric operate, how communicative effects and impacts can be measured, and how relationships between journalists and other communicators are being renegotiated in this emerging new professional context. The question that unites these ideas is how, within a critical perspective, the practice of professional communication affects society, commerce, culture and the individual.

First, let us consider the field of communication, opinion, media and audi- 
ence measurement. As our society moves from paper to digital and from print to oral culture, measurement will be more readily available and in demand. Evolving computational linguistic models of semantic and natural language understanding will provide the tools to parse and study online content, in text, video or audio forms. Communication measurement experts will provide more and more spectacular, real-time interactive visualizations of the evolving landscape - contemporary and historical - of public opinion, attitudes and beliefs. The centrality of metrics and data visualization to public relations, advertising, advocacy and journalism in a digital world will mean that professional communicators will have to have a certain level of numeracy and critical awareness of research methods to be successful. This also means that the field of measurement and data visualization will be an integral part of the larger ethical, theoretical and practical discussions emerging to form the field of professional communication.

Next, let us reflect on the field of public relations and its many sibling fields such as public affairs, communications management and strategic communications, whose theory is shaped and guided by the research conducted in the measurement industry. Traditionally, these interconnected fields define the function of how organizations communicate with their publics. Today, due to emerging and rapidly mutating social media, the questions of how organizations communicate internally and how they relate to the world have become much more complex. This complexity means that communication is rapidly becoming centrally important within organizations, as success in the court of public opinion is becoming a core requirement for the achievement of other strategic objectives. In short, communicators are finding themselves at the decision-making table. Academically, these fields will be integrated into the interdisciplinary field of professional communication, the study of which will be similar to what legal education is to the practice of law - a training ground that produces experts in techniques of establishing, building and maintaining relationships through a rapidly moving kaleidoscope of interconnected media.

Third, let us discuss the field of promotionalism, that is to say the area that encompasses advertising, advocacy and marketing communication, which will find itself integrated into the realm of professional communication, as its role in creating tools and products that aid in persuasion and relationship-building becomes more pronounced, and its new media tools become more ubiquitous, accessible and easily used to produce professional-looking communication products. Knowledge of the theory and practice of promotionalism will be a core competency of the professional communicator. As such, it must be part of the critical, theoretical and ethical conversation within an integrated field of professional communication.

Finally, it is impossible to ignore how journalism is being transformed, as an always-on mediascape pushes the limits of how much content can be created 
and made available to audiences. The lines between journalism and public relations are blurring more and more. This is an unavoidable consequence of the mashing together of communication channels and the democratization of publishing through electronic media. In a world where the average citizen trusts opinions from "people like me" more than those of experts, the role of the journalist is being transformed. Increasingly, journalism is being produced "inhouse", a trend which is drawing the practice of journalism closer to the other practices of professional communication. The example of the News of the World telephone hacking scandal that led to the demise of the United Kingdom's largest-selling daily demonstrates how moving the line between journalism and public relations will necessitate a larger ethical and definitional discussion. This discussion should happen under the aegis of the emerging interdisciplinary field of professional communication.

The future of the field is definitely interdisciplinary. The questions that must be answered require education, training and accreditation, perhaps even licensing and regulation, much as law societies impose the bar exam and an articling period. In fact, this is not a new debate for professional communicators. Edward L. Bernays spent the latter part of his life struggling to have the field of public relations regulated in much the same way as law or accounting is regulated in the United States. In the United Kingdom, the field of public relations has become a chartered profession, governed by the Chartered Institute for Public Relations, which has recently decided to extend membership to professionals practicing the other fields of professional communication. The need to have this debate is growing more pressing as the convergence among the fields comprising professional communications accelerates and the organizational importance of professional communication practitioners grows. Another pressing reason concerns social media: the social media profile of an organization is a function that affects the whole organization, including the highest levels of decision-making. This emerging state of affairs necessitates an integrated perspective on professional communication, which transcends the boundaries of the individual disciplines.

\section{Emergence of academic programs}

The field of professional communication has evolved slowly and incrementally in Canada over the last sixty years. The emergence and growth of mass communication courses and programs, including journalism, public relations and promotion, at Carleton, Ryerson, University of Western Ontario and Laval universities in the 1950s and 1960s foreshadowed the beginning of professional, university-based study and training at post-secondary institutions across Canada. The development of these programs has historically been measured, how- 
ever, today students at almost all colleges and universities have the ability to enrol in communication courses in a diverse range of disciplinary programs at both the undergraduate and graduate levels. While universities and colleges are struggling to cope with the growing demand for post-secondary education, scholars and academic administrators are reporting a rapidly growing interest in the fields of professional communication. For example, to meet this demand, in the last year alone, three new of Bachelor of Public Relations programs have been approved and introduced in Ontario at both Conestoga College and Humber College, and at the University of Ottawa. This is in addition to the forty-four collegiate and university programs that teach public relations in Canada. At the same time, new undergraduate programs in journalism have been launched across Canada increasing the number of college and university or joint programs to nearly fifty.

At the same time, new professionally focused graduate programs have been launched to meet the increasing needs of working professionals whose workplace demands require further instruction, training and research on new communication methodologies, skills and theories. Programs such as the Master of Communications Management at McMaster University, the Master of Public Relations at Mount St. Vincent University and the Master of Professional Communication at Royal Roads University all provide professional communicators with an opportunity to obtain advanced degrees while continuing their careers. One of the intended outcomes of these new graduate programs is an increase in high-quality empirical research, conducted by these students as part of their programs. This new research will expand our understanding and knowledge of these fields from both theoretical and practical perspectives.

The challenge for most of these graduate students and their professors is to find appropriate professional and academic venues in Canada to present and publish their research. The annual conferences of the Canadian Communication Association and the Canadian Public Relations Society only recently engaged the professional communication academic community by highlighting professional and academic research tracks in their conferences. The same applies to the Canadian Journal of Communication, which has very successfully focused on critical and theoretical approaches to communication research. It cannot be debated that presenting scholarly research is an important component of knowledge dissemination and fundamental to the growth and development of an emerging field. Currently, there exists a void in Canadian communications research for an interdisciplinary, peer-reviewed, scholarly journal that encourages both critical and administrative discussion, deliberation and debate about the converging issues in professional communication theory, policy and practice. 


\section{Where does JPC fit in?}

The Journal of Professional Communication was created to start this dialogue. As its diverse editorial advisory board demonstrates, JPC aims to provide a forum for the varied fields of communications to meet, share ideas and exchange opinions. JPC's contents will be varied and eclectic, reflecting the interdisciplinary nature of both the study and practice of professional communication. JPC will publish op-eds, scholarly articles, policy documents, white papers, provocations and book reviews, all of which are represented in this inaugural issue.

It is also wish to emphasize that the JPC is not exclusively a scholarly journal, but rather one that aims to put academics in fruitful dialogue with practitioners and policy makers. The make-up of this first issue, we think, reflects that aim, including contributions from practitioners, seasoned academics and students. We also feature a policy document, "Pathways to the Profession," which was produced by the National Council on Education of the Canadian Public Relations Society (CPRS) and is reproduced here by permission of CPRS, on a one-time license of content. This issue of the JPC is inclusive. We hope that this encourages practitioners, creative professionals, journalists, policy makers, academics and any other invested parties to contribute in the future, so that the emerging field of professional communication has an evolving venue within which to try out new ideas, report on successes and debate pitfalls as we all face an uncharted future of convergence and interdisciplinarity.

\section{Overview of the articles in this issue}

Putting this first issue of the JPC together has been a voyage of discovery. We started by making a general call at the Canadian Public Relations Society meeting in Regina in June of 2010, and also through word-of-mouth. We received thirty submissions of scholarly manuscripts, case studies and book reviews. Of these we have published five scholarly articles, one case study and five book reviews. In addition, we include one guest lecture by James and Larissa Grunig, five op-eds from practitioners in the various fields of professional communication, and an historic education policy document from the Canadian Public Relations Society.

We have a range of op-eds in this issue, covering topics of interest to all professional communicators. In “Open Data: 'There's an App for That'," Joey Coleman discusses how the open data movement is transforming how governments communicate information about how they work. He makes the provocative claim that open data will challenge how journalists and other profes- 
sional communicators do their work. David Estok, in "Paywalls," discusses how the paywall may be a necessary part of the future financial viability of the news media. In "Polling in Election 2011," Nik Nanos discusses the effects and value of polling in elections, using the case of how his firm, Nanos Research, tracked voter attitudes and opinion as an example. Rikia Saddy brings a critical perspective on the social and political impact of social media communications in "Social Media Revolutions." She explains how power and fear should be replaced by more altruistic principles in marketing and public relations, to activate people's hopeful imaginations rather than scaring them into action. Finally, David Scholz, in "The Several Premature Autopsies of AVE," explains, through his own professional experiences, that it is time for to stop using advertising value equivalence as a metric for measuring campaign success.

We are very pleased to present a lecture by those eminent and foundational scholars of public relations, James and Larissa Grunig. We publish in this issue the text of "The Third Annual Grunig Lecture Series: Public Relations Excellence 2010," which they delivered in New York City. The lecture is a reflection on the growing influence and importance of the study of relationships within the public relations profession.

This issue of the JPC offers five fully peer-reviewed scholarly articles, all of which have undergone strict double-blind peer review. Jeremy Berry discusses the importance of writing to the practice of professional communication in "US-Canada Study of PR Writing By Entry-Level Practitioners Reveals Significant Supervisor Dissatisfaction." He forcefully makes the case that there is not enough of a focus on writing in professional communication college and university programs. Denise Brunsdon, in "The Gendered Engagement of Canada's National Affairs \& Legislative Elite, Online," discusses how women in politics and national affairs blog and use Twitter differently from men. Her data suggest that there still exists a gender divide in the emerging arena of online communications. In a French-language article, "L'utilisation du Marketing Politique par les Groupes D'intérêt: Proposition d'un Modèle Théorique, » Émilie Foster presents a model for political marketing that recognizes the important and unique role of special interest groups. Andrew Laing takes us into the realm of media measurement and crisis communication in his article, "The H1N1 Crisis: Roles Played by Government Communicators, Media and the Public." He presents a content analysis suggesting that the public, the media and government communicators all bore a share of the responsibility for the response to the SARS vaccination crisis. Finally, Philip Savage \& Sarah Marinelli explore the gendered nature of the op-ed page in Canadian newspapers in "Sticking to Their Knitting? A Content Analysis of Gender in Canadian Newspaper Op-Eds." They present evidence of a significant gender divide that exists in Canada's op-ed pages, demonstrating that this divide between men and women transcends editorial choice, extending into the arena of 
perceived credibility and the level of willingness to take risks. We also feature one full-length, peer-reviewed case study by Heather Pullen, in the vital and developing area of health communications: "Eastern Health: A Case Study on the Need for Public Trust in Health Care Communications."

This issue presents five reviews of books. Alan Chumley reviews Measure What Matters: Online Tools for Understanding Customers, Social Media, Engagement and Key Relationships by Katie Delahaye Paine, while Rebecca Edgar presents a critical perspective on Putting the Public Back in Public Relations by Brian Solis \& Deirdre Breakenridge, and Laurence Mussio presents a very thoughtful perspective on how information and communication technologies are changing our cognitive capacities in his review of The Shallows by Nicholas Carr. Lars Wessman presents a provocative review of three works discussing the impact of the internet and digital communication on our culture in a comparative review of: The Net Delusion: The Dark Side of Internet Freedom by Evgeny Morozov, You Are Not a Gadget: A Manifesto by Jaron Lanier and Digital Barbarism by Mark Helprin. Finally, Lauren Yaksich discusses how globalization is affecting professional communication in her review of The Global Brand by Nigel Hollis.

To round out this issue, we publish, under special permission of the Canadian Public Relations Society, "Pathways to the Profession," the first thorough characterization of education and training leading to the practice of public relations in Canada.

\section{Our invitation to you}

This issue is large for a reason: it presents a multiplicity of perspectives on the professions of communication. Featured are op-eds, book reviews, scholarly articles, a case study, a policy document, and a guest lecture by two foundational communications scholars. For future editions we encourage you to submit interviews with communication professionals, short informal case studies, squibs, and professional profiles.

It is an important and exciting time to create this new forum for deliberation, and debate among communicators, researchers and teachers in order to advance our knowledge and understanding of the challenges and opportunities that face our unique disciplines.

As such, this journal is meant, certainly, to be a repository of peer-reviewed analysis, knowledge and critique. However, it is also meant to be an arena for opinion, debate, policy discussion, provocation and perhaps even a little storytelling of personal narratives and the histories of those who may have marked us. It is our collective journal, shared among our diverse communities of academics, practitioners, policy makers and artists. You are warmly invited and encouraged to contribute and be heard. 
Sévigny, A. E Flynn, T., Journal of Professional Communication 1(1):3-14, 2011

\section{A note of thanks}

This journal could not have been founded without the support and encouragement of several important friends and colleagues. First and foremost, we would like to thank our generous Dean of Humanities, Suzanne Crosta, who has supported this endeavour since its conception, both materially and through her constant mentorship and encouragement. Great thanks to Jeff Trzeciak, McMaster's chief librarian, whose investment in the BePress digital journal publishing technology made possible the creation of a freely available, open access journal. We would also like to recognize research assistants Morgan Harper and Natalie St. Clair, who both contributed to JPC in its earliest days. A tip of the hat is due to our two proofreaders, Christine Larabie and Dwayne Ali, who kept a watchful eye on the formatting and page layout, catching errors and suggesting improvements. Thanks also to Parker David Martin, who designed JPC's cover layout and art, and to Jonathan Cadle of BePress who provided patient advice on how to use our digital commons electronic publishing engine. Of course, we would be remiss if we did not thank our team of associate editors and our editorial advisory board, whose support is invaluable to JPC's success. A huge thank you to Shelagh Hartford, our tireless assistant editor, whose dedication and passion for detail in reading, editing and APA formatting has made this issue both elegant and readable. Finally, a note of special appreciation for all of our anonymous peer reviewers: without your volunteer support it would be impossible for the machinery of open academic publishing to function on a lean budget.

\section{References}

Fallows, J. (2010, June). How to save the news. The Atlantic. Retrieved from http://www.theatlantic.com/magazine 